\title{
Solving Multi-Objective Energy Management of a DC Microgrid using Multi-Objective Multiverse Optimization
}

\author{
Marouane Lagouir*, Abdelmajid Badri, Yassine Sayouti \\ Department of Electrical Engineering, EEA\&TI Laboratory, Faculty of Science and Technology (FSTM), Hassan II University of \\ Casablanca, BP 146 Mohammedia 20650, Morocco
}

\begin{abstract}
This paper deals with the multi-objective optimization dispatch (MOOD) problem in a DC microgrid. The aim is to formulate the MOOD to simultaneously minimize the operating cost, pollutant emission level of $\left(\mathrm{NO}_{\mathrm{x}}, \mathrm{SO}_{2}\right.$ and $\left.\mathrm{CO}_{2}\right)$ and the power loss of conversion devices. Taking into account the equality and inequality constraints of the system. Two approaches have been adopted to solve the MOOD issue. The scalarization approach is first introduced, which combines the weighted sum method with price penalty factor to aggregate objective functions and obtain Pareto optimal solutions. Whilst, the Pareto approach is based on the implementation of evolutionary multiobjective optimization solution. Single and multi-objective versions of multi-verse optimizer algorithm are, respectively, employed in both approaches to handle the MOOD. For each time step, a fuzzy set theory is selected to find the best compromise solution in the Pareto optimal set. The simulation results reveal that the Pareto approach achieves the best performances with a considerable decrease of 28.96 $\$$ /day in the daily operating cost, a slight reduction in the power loss of conversion devices from $419.79 \mathrm{kWh}$ to $419.29 \mathrm{kWh}$, and in less computational time. While, it is noticing a small increment in the pollutant emission level from $11.54 \mathrm{~kg} / \mathrm{day}$ to $12.21 \mathrm{~kg} / \mathrm{day}$, for the daily microgrid operation. This deviation can be fully covered when comparing the cost related to the treatment of these pollutants, which is only 5.55 \$/day, to the significant reduction in the operating cost obtained using the Pareto approach.
\end{abstract}

Keywords: Multi-objective optimization dispatch, microgrid, weighted sum method, price penalty factor, multi-verse optimizer.

Article History: Received: $7^{\text {th }}$ June 2021; Revised: 25 ${ }^{\text {th }}$ July 2021; Accepted: $5^{\text {th }}$ August 2021; Available online: $18^{\text {th }}$ August 2021

How to Cite This Article: Lagouir, M., Badri, A., Sayouti, Y. (2021) Solving Multi-Objective Energy Management of a DC Microgrid using MultiObjective Multiverse Optimization. International Journal of Renewable Energy Development, 10(4), 911-922

https://doi.org/10.14710/ijred.2021.38909

\section{Introduction}

In recent years, due to the environmental concerns and increasing demand for clean and sustainable energy, development of renewable energy technology has become the focus of several current studies. However, the integration of renewable energy sources (RESs) into the existing power system presents some challenges. This is mainly related to the intermittent and random nature of RESs. If the permanent production from those sources is performed without control, it will increase the power mismatching due to the uncertainties in power generation from RESs, also it will cause fluctuations in voltage and frequency of the main grid (Wang, Sechilariu and Locment. 2012).

Microgrid (MG) concept seems to be a promising alternative for the comprehensive utilization of RESs and other form of distributed generations (DGs) (Liu et al. 2015). A typical MG is consisting of DGs, battery storage system (BSS), and loads.

Generally, it is equipped with an energy management system (EMS) as an essential component in order to improve the reliability and supply security of the system, taking into account the economic and environmental impact associated with the MG operation (Rodríguez del Nozal et al. 2020).
The Multi-objective optimization dispatch (MOOD) is a basic problem in MG system operation. And various objective functions and models have been discussed and developed in the application of the MG such as: minimize the operating cost, minimize the pollutant gas emissions, minimize the cycle degradation of the battery storage system (Feng et al. 2020), minimize the power loss of the system (Zhang et al. 2020), maximize the comfort and the economic benefit of the end users by including demand side management approach (Lokeshgupta and Sivasubramani. 2018) in the formulated problem.

There are many potential ways to deal with the multiobjective optimization problem (MOOP). The scalarization approach requires the transformation of the MOOP into a single objective optimization. The weighted sum method (WSM) is widely considered to formulate the optimization problem. Then the Pareto optimal front can be obtained through multiple runs using well-known metaheuristic algorithms. In (Mondal, Bhattacharya and nee Dey. 2013), the authors discuss the application of the gravitational search algorithm (GSA) to solve the economic emission load dispatch problem, considering the penetration of wind power. The price penalty factor (PPF) is introduced to convert the multi-objective problem into a single one. Then the set of Pareto optimal solutions (POSs) was

\footnotetext{
* Corresponding author: lagouir.mar1@gmail.com
} 
generated using weighting factor. The results obtained by GSA have been compared with those of biogeographybased optimization. They reveal that GSA outperforms the biogeography-based optimization in terms of solution quality and computational efficiency. The authors in (Abdullah et al. 2015), propose a modified particle swarm optimization with time-varying acceleration coefficients (MPSO-TVAC) for economic emission load dispatch optimization. Similarly, a combination of PPF (Zhang, Gong and Ding. 2012) and WSM has been adopted to aggregate the objective functions and to find the POSs of the formulated problem, then the best compromise solution is determined based on a fuzzy ranking approach.

However, current studies trend toward the application of the evolutionary multi-objective algorithms to approximate the Pareto set of the MOOP. In (Aghajani and Ghadimi. 2018) a multi-objective particle swarm optimization (MOPSO) method was employed for dayahead energy management, considering the operation cost and emission rate as objective functions to be minimized. Then the results are compared with non-dominated sorting genetic algorithm II (NSGA-II) technique, to show the superior performance of the proposed method.

The research in (Sundaram. 2020), proposed the implementation of Multi-objective multi-verse optimizer (MOMVO) algorithm to solve both the combined economicemission dispatch and the combined heat and power economic emission dispatch problems. Considering challenging constraints such as valve-point effects, ramp rate limits and the feasible operating region of cogeneration units. The statistical analysis proves the ability of the proposed method to provide better solutions compared to existing methods in literature such as NSGA II, MOPSO and others. The authors in (Ghiasi et al. 2021) solved the energy management of a MG consisting of various DGs. The optimization problem is formulated to simultaneously minimize the total operational costs and the environmental pollution effects. An improved multiobjective differential evolutionary optimization algorithm is suggested to handle the optimization problem.

Recently, there has been a growing interest in proposing new and hybrid optimization algorithms to deal with the MOOD problem in MG system. Multi-objective fireworks algorithm with gravitational search operator (MFAGSO) (Wang et al. 2017), MOPSO method (Aghajani and Ghadimi. 2018), Antlion optimizer algorithm (Kamboj, Bhadoria and Bath. 2017; Alazemi and Hatata. 2019; Hatata and Hafez. 2019; Van, Snasel and Nguyen. 2020), NSGA-II optimization method (Contreras, Cortes and Myrzik. 2019), strength Pareto evolutionary algorithm (Yuan et al. 2017), MPSO-TVAC (Abdullah et al. 2015), multi-objective grey wolf optimization (Haseeb et al. 2020).

In this paper the multi-objective optimization dispatch problem has been solved using both approaches. The scalarization method is first implemented. It is based on the application of the WSM with PPF in order to convert the MOOD problem into a single objective function, then the Pareto sets is obtained through multiple runs by adjusting the weight coefficients. Finally, for each combination of weights, the single version of multi-verse optimizer (MVO) algorithm is selected to handle the formulated optimization problem. On the other hand, the Pareto approach requires the application of the MOMVO based evolutionary multi-objective algorithm to deal with the considered conflicting objective functions.

The MOOD is formulated in order to minimize simultaneously three contradictory objective functions representing: the overall operating cost, the emissions level of $\left(\mathrm{NO}_{\mathrm{x}}, \mathrm{SO}_{2}, \mathrm{CO}_{2}\right)$, and the power loss of the conversion devices, taking into account the technical constraints of the system (Taha, Abdeltawab and Mohamed. 2018). Finally, to determine the best compromise solution from POSs, integrated a decisionmaking based on a fuzzy set theory is successfully employed. To validate the robustness and efficiency of the proposed approaches, the performance of both techniques is compared.

The paper is organized as follows: Section 2 details the formulated optimization problem. Section 3 is dedicated to describing the proposed two approaches to solve the multiobjective optimization dispatch problem. The obtained simulation results are presented and discussed in Section 4. Finally, Section 5 concludes the work.

\section{Problem Formulation}

The MG under study is running under grid connected mode. Fig. 1 shows the architecture of the proposed MG power system. It mainly contains photovoltaic (PV) system and wind turbine (WT) modules as RESs. Three conventional energy sources (CESs), respectively represented by a diesel engine (DE), fuel cell (FC) unit and a micro-turbine (MT) as well as an energy storage system (ESS). These components are controlled by a centralized EMS, and the connection to the main grid is ensured through a point of common coupling (PCC). Meanwhile, the MG system includes a number of power conversion devices, which are mainly AC/DC and DC/DC conversion devices.

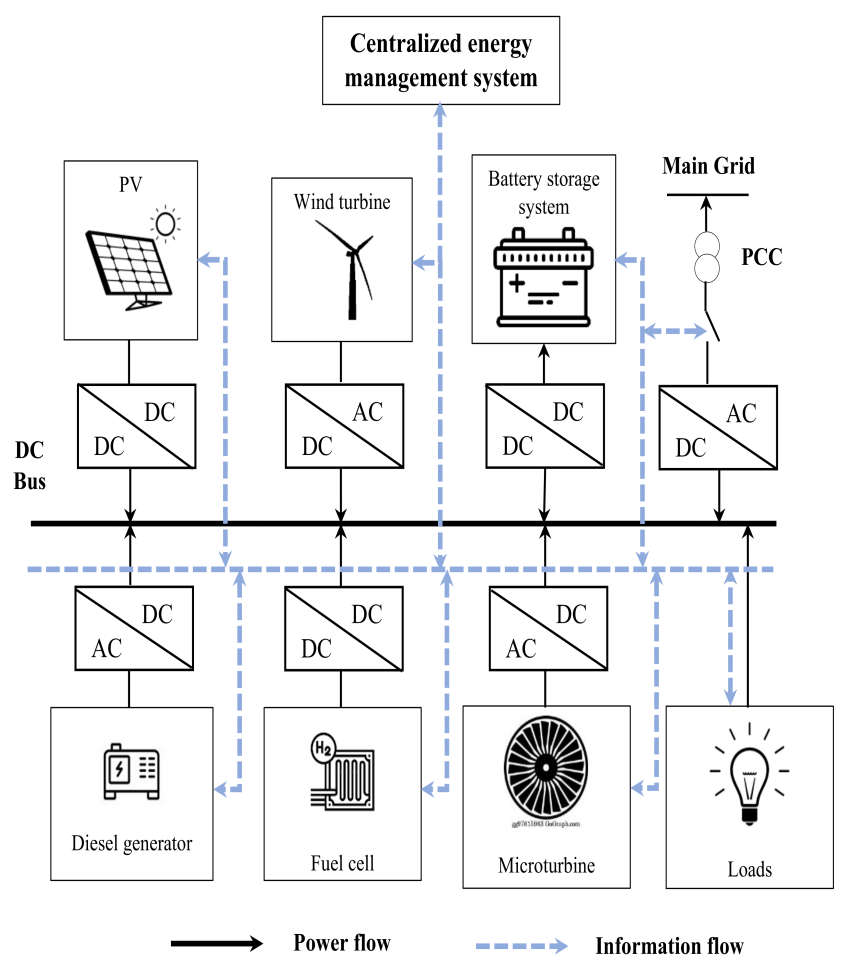

Fig. 1 Architecture of the studied MG under grid connected mode 


\subsection{Control Strategy of the DC Microgrid}

In grid connected mode, the MG system exchanges power with the main grid through purchasing or selling electricity. The control strategy of the studied DC microgrid is detailed as follows, and it is depicted in the flowchart of Fig. 2:

- The load is mainly supplied by both PV generation system and WT modules as they are sustainable and clean sources.

- When the load is low, and there is an abundance of the power generated from RESs. The excess of power will be used for charging the BSS. Once the battery reaches a maximum state of charge (SoC), the remaining power will be sold to the main grid.

- During peak periods of load, when the combined output power of both RESs and the BSS during discharging cycles cannot meet the peak load. The EMS incorporates the three CESs in the energy management, while permitting the import of power from the main grid. The participation of each element in the energy management will be limited to its response to the formulated MOOD problem.

- During the transaction process with the main grid, if a grid failure is caused the load shedding option should be taken into consideration. Meaning that the power generation will be limited to the internal MG's sources only, given priority to supply the critical load.

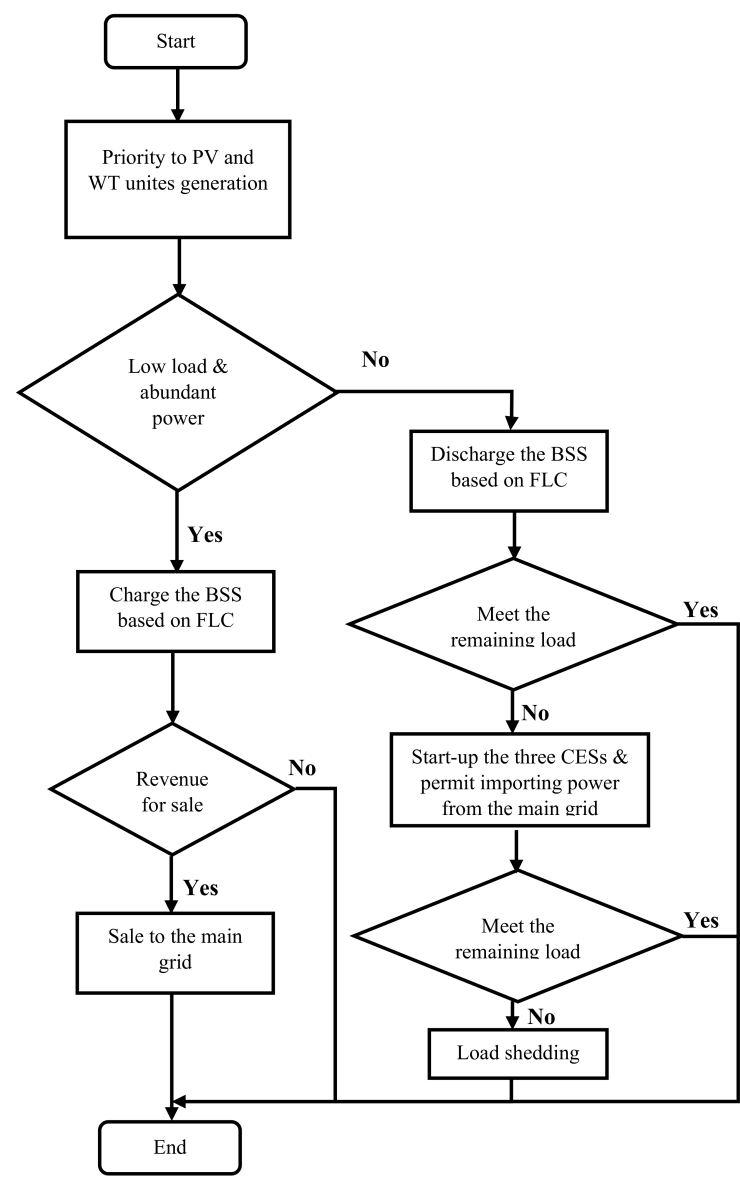

Fig. 2 Flowchart of the proposed strategy control in grid connected mode

\subsection{Modelling of the Multi-Objective Optimization Dispatch Problem}

Beside the operation control of the MG's components, the developed EMS is designed with the aim to handle the MOOD problem, considering technical, economic and environmental tasks simultaneously. The operating cost of the MG power system is defined as the first objective function to be minimized, followed by the pollutant gas emissions of nitrogen oxide, sulfur dioxide and carbon dioxide $\left(\mathrm{NO}_{\mathrm{x}}, \mathrm{SO}_{2}\right.$ and $\left.\mathrm{CO}_{2}\right)$, respectively. Finally, the third objective function is the power loss of the conversion devices.

Two approaches are proposed to solve the MOOD problem. The scalarization method based on the application of PPF with WSM to transform the multiobjective optimization problem into a single-objective problem and to find the Pareto optimal solutions. A set of feasible solutions could be obtained by assigning various combinations of weight coefficients to the formulated objective function (Abdullah et al. 2015).

As regards the Pareto approach, depends on the application of multi-objective optimization solution directly to the formulated problem. Therefore, the MOMVO algorithm is applied to deal with the MOOD problem. Fig. 3 provides an illustrative presentation of the two approaches. Finally, the mathematical formulations of the three contradictory objective functions are described in the following subsection.

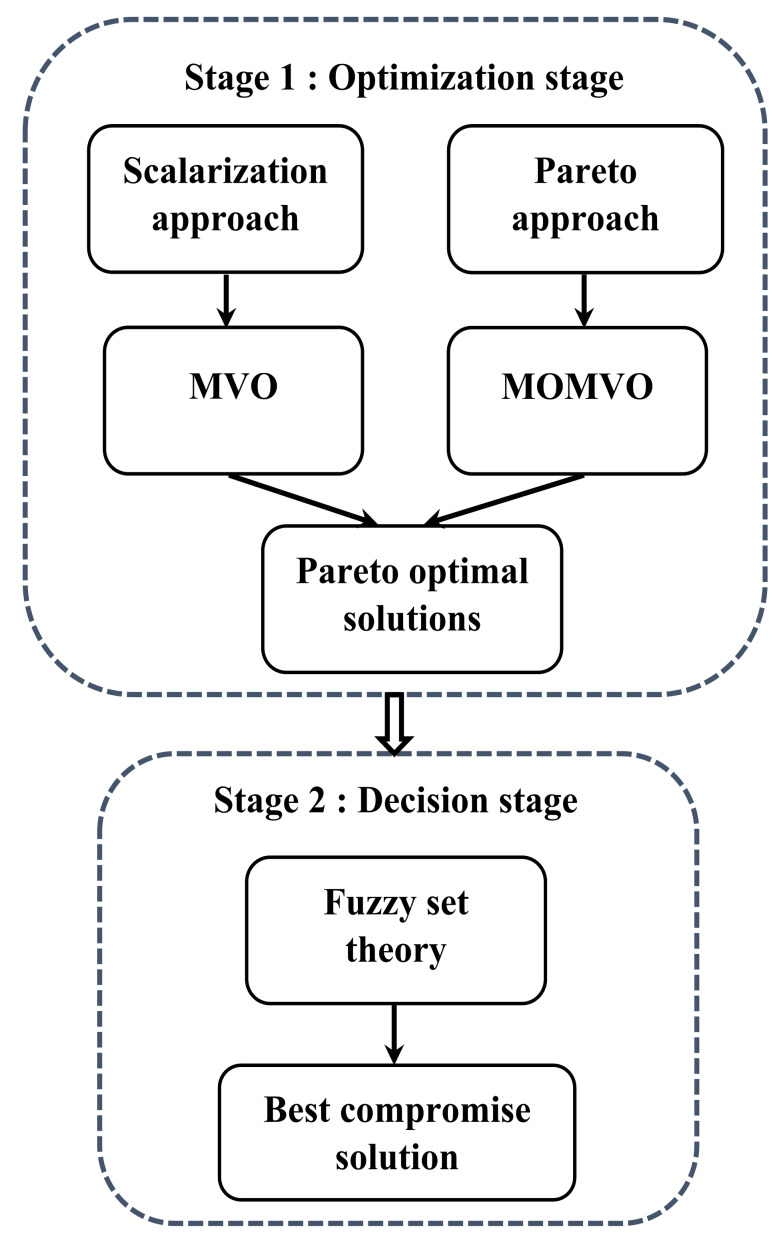

Fig. 3 Illustrative presentation of the proposed two approaches to solve the MOOD 


\subsubsection{Minimization of the operating cost function}

The primary concerning of the proposed energy management approach is the minimizing of the operating cost. It consists of the fuel cost of generators $C F$, operation \& maintenance cost $C^{O \& M}$, start-up cost $C^{S T U}$ and the transaction cost of exchanging power with the main grid $C_{t r}$ (Mohamed and Koivo. 2012; Moradi et al. 2018; Nemati, Braun and Tenbohlen. 2018; AlvaradoBarrios et al. 2019; Dey, Shivam and Bhattacharyya. 2019; Wang, He and Deng. 2019):

$$
\begin{aligned}
F_{1} & =\sum_{t=1}^{T} \sum_{i=1}^{N}\left\{C F_{i}\left(P_{i}(t)\right)+C_{i}^{O \& M}\left(P_{i}(t)\right)+C_{i}^{S T U}\right\} \\
& +\sum_{t=1}^{T} C_{t r}\left(P_{t r}(t)\right)
\end{aligned}
$$

$C_{i}^{O \& M}=\sum_{i=1}^{N} K_{O \& M_{i}} P_{i}(t)$

$$
C_{i}^{S T U}=\sigma_{i}+\delta_{i}\left[1-\exp \left(-\frac{T_{o f f, i}}{\tau_{i}}\right)\right]
$$$$
C_{t r}\left(P_{t r, \text { Grid }}(t)\right)=\left\{\begin{array}{l}
C_{P} \times P_{t r, \text { Grid }}(t) ; \text { Main grid to MG } \\
0 ; \text { disconnected } \\
-C_{s} \times P_{t r, \text { Grid }}(t) ; \text { MG to the Main grid }
\end{array}\right.
$$

\section{Where}

- $\alpha_{i}, \beta_{i}, \gamma_{i}$ denote the cost coefficients of generating unit $i$,

- $K_{O \& M_{i}}$ is the operation and maintenance cost coefficient in $[\$ / \mathrm{kWh}]$,

- $\quad P_{i}$ is the active power output of generating unit $i$,

- $\sigma_{i}, \delta_{i}$ represent respectively, hot and cold start-up cost,

- $\tau_{i}$ is the constant of cooling time,

- $C_{P}$ is the cost of purchasing electricity from the main grid in $[\$ / \mathrm{kWh}$,

- $\quad C_{S}$ is the cost of selling electricity to the main grid in $[\$ / \mathrm{kWh}]$, and

- $P_{t r, \text { Grid }}$ indicates the power of the transaction with the main grid.

Equation (1) represents the operating cost of the MG power system, while Eq. (2), (3), (4) and (5) describe the mathematical formulas used for calculating the cost of each term, respectively. It is worth mentioning, that the actual generated power from each dispatchable source may vary in the range from 0 to the rated power, and the fuel consumed is approximated as a quadratic function of the output power given as Eq. (2). Regarding the operation \& maintenance cost, it can be formulated as a linear function of the generated power as shown in Eq. (3). Furthermore, the transaction cost of the exchanged power with the main grid could have a positive value whenever the MG import power from the main grid, or represented by a negative value in case of selling power to the main grid. Finally, a null value refers to the disconnected mode, in case of a grid failure as formulated in Eq. (5).

The adopted electricity price profile for each hour of the day is shown in Fig. 4, it is given similar to the data provided in (Nemati, Braun and Tenbohlen. 2018). Where the maximum and the minimum cost of purchasing electricity from the main grid are set at $0.288 \$ / \mathrm{kWh}$ and $0.152 \$ / \mathrm{kWh}$, respectively.

\subsubsection{Minimization of the pollutant gas emissions cost function}

The second objective function to be minimized is the pollutant gas emissions cost of $\mathrm{NO}_{\mathrm{x}}, \mathrm{SO}_{2}$ and $\mathrm{CO}_{2}$, respectively. Mathematically formulated as a linear function of the produced power (Wu, Liu and Ding. 2014; Liu et al. 2015; Nemati, Braun and Tenbohlen. 2018):

$$
F_{2}=\sum_{i=1}^{T}\left\{\sum_{i=1}^{N} \sum_{k=1}^{M} \chi_{k}\left(E F_{i, k} P_{i}\right)+\sum_{k=1}^{M} \chi_{k}\left(E F_{\text {Grid }, k} P_{t r, \text { Grid }}\right)\right\}
$$

Where

- $\quad \chi_{k}$ denotes the externality cost for emission type $k$ in $[\$ / \mathrm{kg}]$,

- $\quad N$ is the number of generating unit,

- $M$ is the total number of the types of atmospheric pollutants $\left(\mathrm{NO}_{\mathrm{x}}, \mathrm{SO}_{2}, \mathrm{CO}_{2}\right)$,

- $T$ is the total number of running hours,

- $E F_{i, k}$ is the pollutant emission coefficient of the generating unit $i$ in $[\mathrm{kg} / \mathrm{kWh}]$, and

- $E F_{G r i d, k}$ is the pollutant emission coefficient of the main grid, for emission type $k$ in $[\mathrm{kg} / \mathrm{kWh}]$.

Table 1 and Table 2 present respectively, a detailed specification of the operating and the emission parameters used (Mohamed and Koivo. 2012; Moradi et al. 2018; Nemati, Braun and Tenbohlen. 2018; Alvarado-Barrios et al. 2019; Murty and Kumar. 2020).

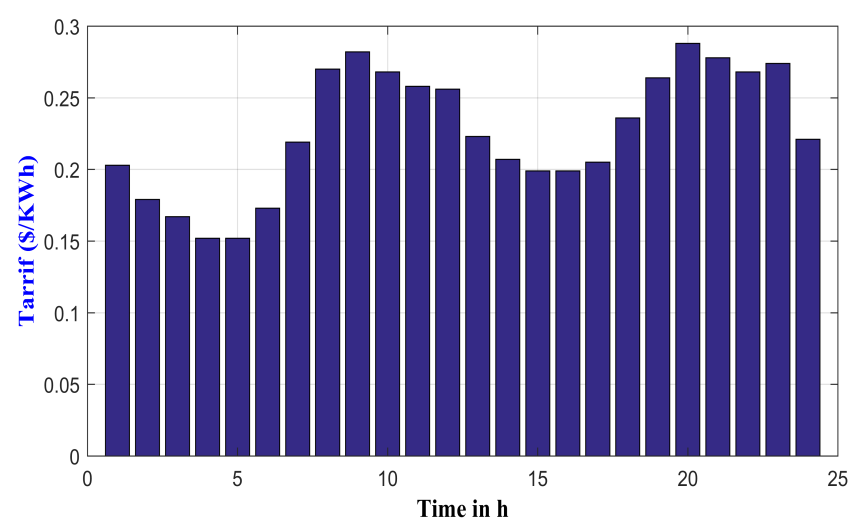

Fig. 4 Hourly electricity price profile 
Table 1

Operating cost parameters of conventional energy sources and main grid

\begin{tabular}{|c|c|c|c|c|c|c|c|c|}
\hline & \multirow{2}{*}{$\begin{array}{l}\mathbf{P}_{\text {rated }} \\
P_{i}[\mathrm{~kW}]\end{array}$} & \multicolumn{3}{|c|}{ Fuel or gas cost coefficients } & \multicolumn{3}{|c|}{ Start-up cost } & \multirow{2}{*}{$\begin{array}{c}\text { O\&M cost } \\
K_{O M_{i}}[\$ / \mathrm{kWh}]\end{array}$} \\
\hline & & $\alpha_{i}[\$ / \mathrm{h}]$ & $\beta_{i}[\$ / \mathrm{kWh}]$ & $\gamma_{i}\left[\$ / \mathrm{kW}^{2} \mathrm{~h}\right]$ & $\sigma_{i}[\$ / \mathrm{h}]$ & $\delta_{i}[\$ / \mathrm{h}]$ & $\tau_{i}$ & \\
\hline DG & 40 & 2.22 & 0.2328 & 0.0024 & 0.3 & 0.4 & 5.2 & 0.01258 \\
\hline FC & 50 & 0.1037 & 0.1855 & 0.0009 & 0.35 & 0.26 & 5.2 & 0.00419 \\
\hline MT & 65 & 2.898 & 0.2668 & - & 0.4 & 0.28 & 7.1 & 0.00587 \\
\hline Grid & 50 & - & - & - & - & - & - & - \\
\hline
\end{tabular}

Table 2

Externality costs parameters and the emission coefficients

\begin{tabular}{lccccc} 
& $\begin{array}{c}\chi_{k} \\
{[\$ / \mathbf{k g}]}\end{array}$ & $\begin{array}{c}\text { DG } \\
{[\mathbf{k g} / \mathbf{M W h}]}\end{array}$ & $\begin{array}{c}\text { FC } \\
{[\mathbf{k g} / \mathbf{M W h}]}\end{array}$ & $\begin{array}{c}\text { MT } \\
{[\mathbf{k g} / \mathbf{M W h}]}\end{array}$ & $\begin{array}{c}\text { Main } \\
\text { grid } \\
{[\mathbf{k g} / \mathbf{M W h}]}\end{array}$ \\
\hline NOx $_{\mathbf{2}}$ & 9.1714 & 9.8883 & 0.0136 & 0.1995 & 1.6021 \\
SO$_{2}$ & 2.1617 & 0.2059 & 0.0027 & 0.0036 & 1.8016 \\
$\mathbf{C O}_{2}$ & 0.0305 & 0.6495 & 0.4889 & 0.7239 & 1.8891 \\
\hline
\end{tabular}

\subsubsection{Minimization of the power loss cost function}

The third term of the MOOD problem is used to evaluate the power loss of the conversion devices in the MG power system. It is defined as follows (Wu et al. 2019):

$F_{3}=\sum_{t=1}^{T}\left\{\sum_{i=1}^{N} C_{\text {loss }_{i}} P_{\text {loss }_{i}}\right\}=\sum_{t=1}^{T}\left\{\sum_{i=1}^{N} \sigma_{\text {loss }_{i}} C_{\text {loss }_{i}} P_{i}\right\}$

Where

- $\sigma_{\text {loss }_{i}}$ is the coefficient of conversion power loss,

- $C_{\text {loss }_{i}}$ stands for the penalty of the power loss cost function in $[\$ / \mathrm{kWh}]$, and

- $P_{\text {loss }_{i}}$ indicates the power loss of conversion device connected to the generator $i$.

It is worth mentioning that according to (Wu et al. 2019 ), this power loss may vary between $2 \%$ and $16 \%$ of conversion power. Therefore, in this work the coefficient of conversion power loss $\sigma_{\text {loss }}$ of $\mathrm{FC}$ is set to $2 \%, 4 \%$ when we make use of the generated power of DG or MT unit. Finally, this coefficient is equal to $6 \%$ in case of exchanging power with the main grid.

\subsubsection{System constraints}

The above formulated multi-objective problem is optimized considering the technical operation constraints given as described hereafter.

During the operation of the MG system, the power balance should be preserved. This means that the power output from all the installed dispatchable and nondispatchable DG unites, including the exchanged power with the main grid and the BSS must be equal to the load demand and the power loss. It is defined as follows:

$P_{D}(t)+P_{\text {loss }}(t)=\left\{\begin{array}{c}P_{t r, \text { Grid }}(t)+P_{C E S_{S}}(t) \\ +P_{B S S}(t)+P_{R E S_{S}}(t)\end{array}\right\}$
In each time period, the output power of each distributed generation should be bounded within its allowable range, the technical constraints are given in the following:

$$
\begin{gathered}
P_{D E_{M i n}} \leq P_{D E} \leq P_{D E_{M a x}} \\
P_{F C_{M i n}} \leq P_{F C} \leq P_{F C_{M a x}} \\
P_{M T_{M i n}} \leq P_{M T} \leq P_{M T_{M a x}} \\
P_{t r, \text { Grid }} \leq P_{t r, \text { Grid }} \leq P_{t r, \text { Grid }} \\
P_{B S S_{M i n}} \leq P_{B S S} \leq P_{B S S_{M a x}} \\
0 \leq P_{P V} \leq P_{P V_{M p p t}} \\
0 \leq P_{W T} \leq P_{W T_{M p p t}}
\end{gathered}
$$

\section{Proposed Methods to solve the MOOD Problem}

In this work, two methodologies are adopted to deal with the MOOD problem in the studied MG system. The following subsections detail the mathematical formulation of the optimization problem using both approaches, as well as an overview of single and multi-objective version of MVO algorithm used to solve the MOOD problem.

\subsection{Scalarization Method}

The scalarization method (Augusto, Bennis and Caro. 2012; Gunantara. 2018) is primarily described. It is based on combining WSM with PPF to convert the MOOD problem into a single objective optimization. In the search space, a set of feasible solutions, can be obtained through multiple simulation runs, by assigning different combinations of weight coefficients $\omega_{1}, \omega_{2}$ and $\omega_{3}$, to their associated objective functions. Mathematically the MOOD problem is formulated by Eq. (10) (Liu et al. 2015). Given as follows:

$$
\min O F_{M G}=\sum_{t=1}^{T} \sum_{i=1}^{3} \omega_{i} F_{i}(x)
$$

Fig. 5 illustrated the various combinations of weight coefficients obtained over 150 runs (Stafford. 2021). It is to be noted that, for each simulation run, which corresponds to a specific combination of weights, the following constraint should be taken into account:

$\omega_{i} \geq 0$ and $\sum_{i=1}^{3} \omega_{i}=1$ 


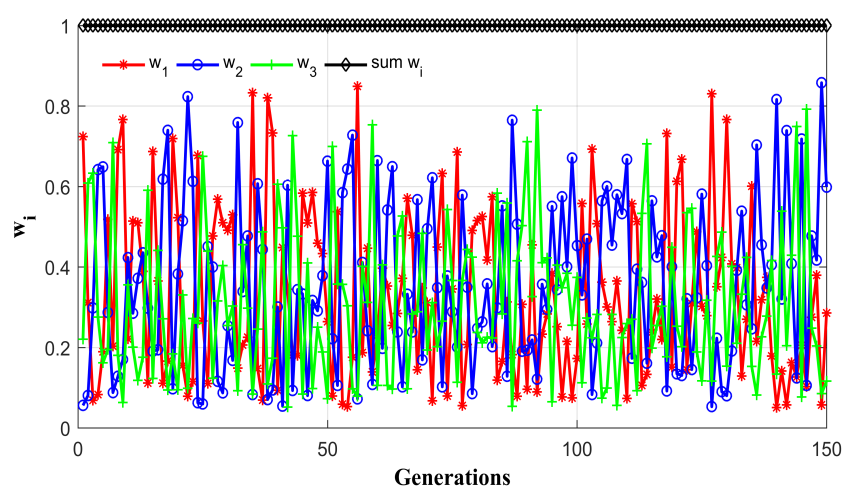

Fig. 5 Combination of weight coefficients adopted in the scalarization approach

Once all the feasible solutions are generated, the next step requires the determination of the Pareto optimal solutions from the feasible set. Assumed that $x_{1}$ and $x_{2}$ are two solutions of the MOOP, two cases are possible: one solution dominates the other or none dominates the other (Zhang, Gong and Ding. 2012). Therefore $x_{1}$ is considered to dominate $x_{2}$ if and only if:

$\left\{\begin{array}{l}F_{i}\left(x_{1}\right) \leq F_{i}\left(x_{2}\right) \quad \forall i \in\left\{1,2, \ldots N_{O}\right\} \\ F_{i}\left(x_{1}\right)<F_{i}\left(x_{2}\right) \quad \exists i \in\left\{1,2, \ldots N_{O}\right\}\end{array}\right.$

The non-dominated solutions of the entire feasible search space are called Pareto optimal solutions. Which form the Pareto optimal set (Zhang, Gong and Ding. 2012; Feng et al. 2020).

\subsection{Pareto Method}

The second approach to deal with the MOOD problem is by applying evolutionary multi-objective optimization (Mirjalili et al. 2017). Using such algorithms have the advantage of producing the Pareto optimal front in a single run (Sundaram. 2020). Therefore, MOMVO algorithm is selected to handle the formulated optimization problem.

Unlike the scalarization method whose objective functions are related to each other by weight coefficients. The Pareto method (Gunantara. 2018), (Dey and Choudhury. 2017) handle the MOOD problem independently. The mathematical model of the optimization problem is represented bellow (Sundaram. 2020):

$$
\begin{aligned}
& \min O F_{M G}=\sum_{t=1}^{T}\left[F_{1}(x), F_{2}(x), F_{3}(x)\right], x \in D \\
& D=\left\{\begin{array}{l}
x: g_{j}(x) \leq 0, \mathrm{~h}_{k}(x)=0 ; \\
j=1,2, \ldots, J ; \mathrm{k}=1,2, \ldots, K
\end{array}\right\} \\
& x=\left[x_{1}, x_{2}, x_{3} \ldots, x_{n}\right]^{T} \\
& x_{i}^{\min } \leq x_{i} \leq x_{i}^{\max }
\end{aligned}
$$

Where

- $J$ is the number of inequality constraints $g(x)$,

- $K$ is the number of equality constraints $h(x)$,

- $x_{i}^{\text {min }}$ is the lower bound of the decision variable $x$,

- $x_{i}^{\max }$ is the upper bound of the decision variable $x$, and

- $\quad D$ is the feasible search space.

The decision variable $x$ contains the power output of the three CESs represented respectively by DE, FC and MT, as well as the exchanged power with the main grid.

\subsection{Overview of Single and Multi-Objective Version of MVO Algorithm}

The Multi-verse optimizer algorithm, is first introduced by Seyedali Mirjalili et al. in 2016 (Mirjalili, Mirjalili and Hatamlou. 2016). It mimics one of the theory in physics related to the existence of multiple universes in the world. The mathematical modelling of three concepts in cosmology (white hole, black hole and wormhole) are developed to perform exploration, exploitation and local search in the MVO.

This algorithm seems to be a promising solution to solve real-world problem, since the comparison results prove its ability to provide very competitive results and outperforms well-known algorithms in literature (Mirjalili, Mirjalili and Hatamlou. 2016). Thus, this work employs the single and multi-objective version of MVO (Mirjalili et al. 2017) algorithm to deal with the MOOD problem in MG power system.

Generally, the objects in the universes tend always to move from high inflation rate universe toward low inflation rate one via white/black hole tunnels, to accomplish a stable state.

Assuming that, we have $n$ number of universes (candidate solutions in MVO), with $d$ objects (refers to variables in MVO).

$U=\left[\begin{array}{cccc}x_{1}^{1} & x_{1}^{2} & \cdots & x_{1}^{d} \\ x_{2}^{1} & x_{2}^{2} & \cdots & x_{2}^{d} \\ \vdots & \vdots & \vdots & \vdots \\ x_{n}^{1} & x_{n}^{2} & \cdots & x_{n}^{d}\end{array}\right]$

Mathematically, the mechanism of exchanging objects between universes is formulated as follows (Mirjalili, Mirjalili and Hatamlou. 2016):

$x_{i}^{j}= \begin{cases}x_{k}^{j} & r_{1}<N I\left(U_{i}\right) \\ x_{i}^{j} & r_{1} \geq N I\left(U_{i}\right)\end{cases}$

Where

- $\quad N I\left(U_{i}\right)$ is the normalized inflation rate of $i^{\text {th }}$ universe. 
The exploitation mechanism is explained using the following formula (Mirjalili, Mirjalili and Hatamlou. 2016):

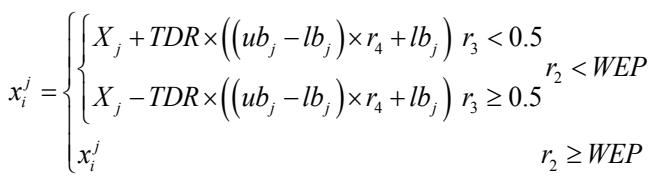

where

- $\quad r_{1}$ to $r_{4}$ are random numbers in $[0,1]$ interval,

- $W E P$ is coefficient stand for wormhole existence probability,

- $T D R$ is coefficient stand for travelling distance rate,

- $X_{j}$ is the $j^{\text {th }}$ parameter of best universe formed,

- $u b_{j}$ is the upper bound of $j^{\text {th }}$ parameter of best universe formed and

- $\quad l b_{j}$ is the lower bound of $j^{\text {th }}$ parameter of best universe formed.

The formula used to calculate the wormhole existence probability and the travelling distance rate are as follows (Mirjalili, Mirjalili and Hatamlou. 2016):

$W E P=W E P_{\min }+l \times\left(\frac{W E P_{\max }-W E P_{\min }}{L}\right)$

$T D R=1-\frac{l^{1 / p}}{L^{1 / p}}$

Where

- $W E P_{\text {min }}$ is the minimum of wormhole existence probability, it is set to 0.2 ,

- $W E P_{\max }$ denotes the maximum of wormhole existence probability, it is set to 1 ,

- $\quad l$ is current iteration,

- $\quad L$ is maximum iteration, and

- $\quad p$ is the exploitation accuracy over the iterations, it has a typically value of 6 (Mirjalili, Mirjalili and Hatamlou. 2016).

The flowchart of Fig. 6 summarized the main steps of MVO algorithm (Fathy and Rezk. 2018). It is to be noted that the search mechanism in the multi-objective version of MVO is similar to the one provided with the above steps in the single version of MVO. Moreover, an archive with a leader selection updating mechanism are also employed to improve the diversity of nondominated solutions (Mirjalili et al. 2017; Sundaram. 2020).

\subsection{Compromise Solution based on Fuzzy Logic Theory}

For this case study, a fuzzy logic approach is adopted to identify the appropriate solutions from the obtained Pareto optimal sets.

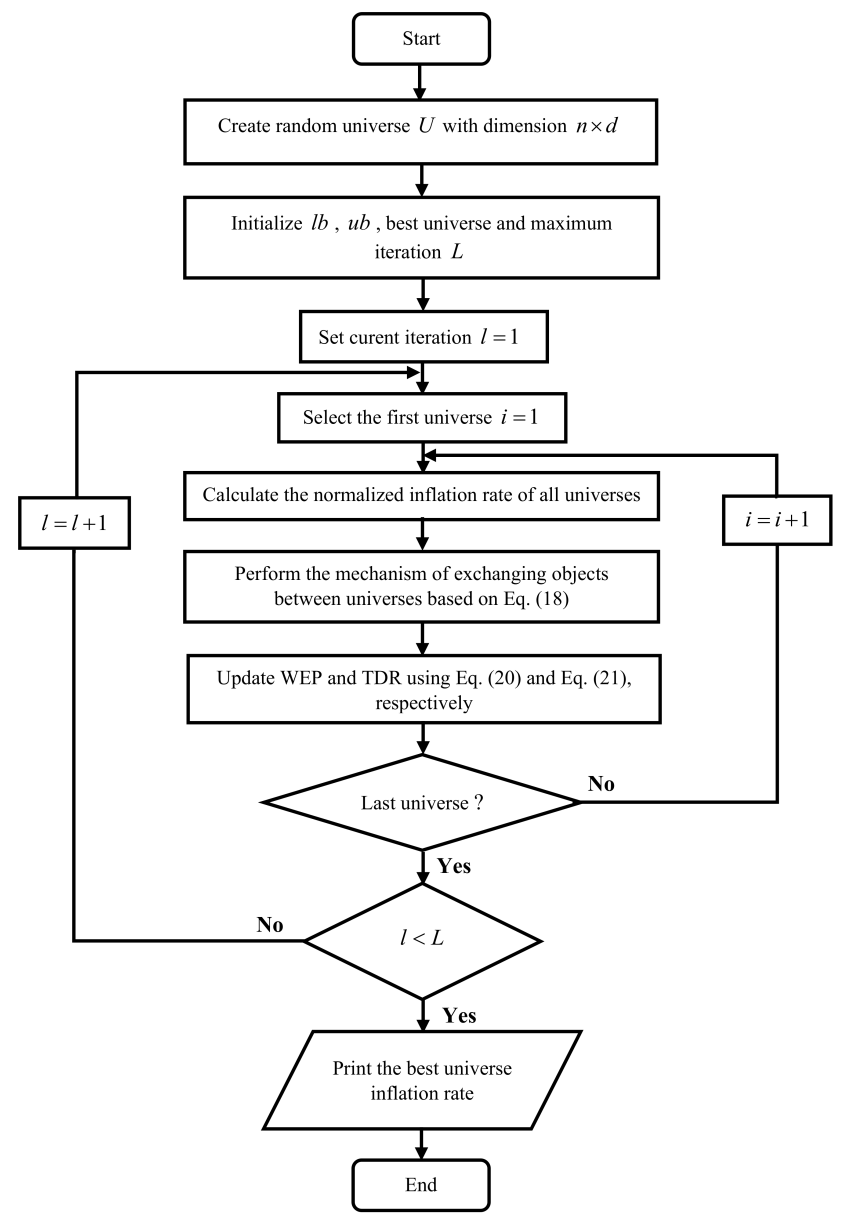

Fig. 6 The main steps of multi-verse optimizer algorithm

The first step in the fuzzy logic method is to convert each objective function $F_{i}$ into its corresponding fuzzy membership function. It represents the degree of the membership $\mu\left(F_{i}\right)$ in the fuzzy sets. Mathematically, this is formulated using the following equation:

$$
\mu\left(F_{i}\right)= \begin{cases}1 & F_{i} \leq F_{i}^{\min } \\ \frac{F_{i}^{\max }-F_{i}}{F_{i}^{\max }-F_{i}^{\min }} & F_{i}^{\min } \leq F_{i} \leq F_{i}^{\max } \\ 0 & F_{i} \geq F_{i}^{\max }\end{cases}
$$

It is worth mentioning that a null membership value refers to incompatibility of the membership with the fuzzy sets. While a value of 1 corresponds to a full compatibility (Mondal, Bhattacharya and nee Dey. 2013).

The next step, involves calculating the normalized membership function $\mu^{k}$ given as follows (Mondal, Bhattacharya and nee Dey. 2013; Hou et al. 2020):

$\mu^{k}=\frac{\sum_{i=1}^{N_{O}} \mu^{k}\left(F_{i}\right)}{\sum_{k=1}^{M} \sum_{i=1}^{N_{O}} \mu^{k}\left(F_{i}\right)}$ 


\section{Where}

- $\quad M$ indicates the number of non-dominated solutions, and

- $N_{O}$ represents the considered objective functions in number.

\section{Results and Discussions}

In this section, the proposed two approaches have been successfully implemented to solve the MOOD problem in MG power system. To validate the performance, simulation is carried out for a day ahead energy management of a typical MG running under grid connected mode. The optimization problem is modelled and simulated in MATLAB/Simulink environment, with a time step of $\Delta \mathrm{T}=15 \mathrm{~min}$ (Aluisio et al. 2017; Cheng et al. 2020). The aim is to find the best compromise between the above described contradictory objective functions. Taking into account maximize the generation from RESs, optimal charging/discharging of BSS based on a fuzzy logic control, and the system technical constraints.

\subsection{Result Analysis of the Multi-Objective Model}

In the search space, to obtain the feasible solutions, the scalarization approach is based on assigning different combinations of weight coefficients $\left(\omega_{1}, \omega_{2}\right.$ and $\left.\omega_{3}\right)$ to the formulated objective function. In addition, to capture the non-dominated solutions only the formula provided in Eq. (12) is applied. Finally, a fuzzy set approach is adopted for selection of the best compromise solution in the Pareto optimal set.

Fig. 7 shows the POSs obtained using both approaches and considering the operating cost and emissions level as objective functions to be minimized. Whereas, the distribution of the POSs using both approaches and considering the minimization of the three conflicting objective functions is illustrated in Fig. 8. Where, the best compromise results of both approaches using the fuzzy set are provided in Fig. 9. The operating cost and pollutant emission value were, respectively, plotted on the $\mathrm{X}$-axis and the $\mathrm{Y}$-axis. While the $\mathrm{Z}$-axis was reserved to represent the value of power loss.

By comparing the Pareto optimal sets obtained for a fixed load demand $\mathrm{P}_{\mathrm{D}}=32 \mathrm{~kW}$, it is clearly seen that the Pareto approach provides more closely and uniform set. Therefore, it is obvious that the Pareto approach is not only able to give better diversity and better quality solutions than the scalarization technique, but also a better compromise solution. In addition, contrary to the scalarization method that requires multiple simulation runs. The Pareto method (Gunantara. 2018), presents the advantage to find the Pareto optimal set in a single run and in less computational time. Moreover, according to (Zhang, Gong and Ding. 2012) the scalarization technique is expected to fail to provide a well distributed solutions in case of nonconvex problem.

It is worth mentioning that, the single and multiobjective version of MVO applied in both approaches for solving the optimization problem are running using a population size of 40 and maximum iterations of 200 .

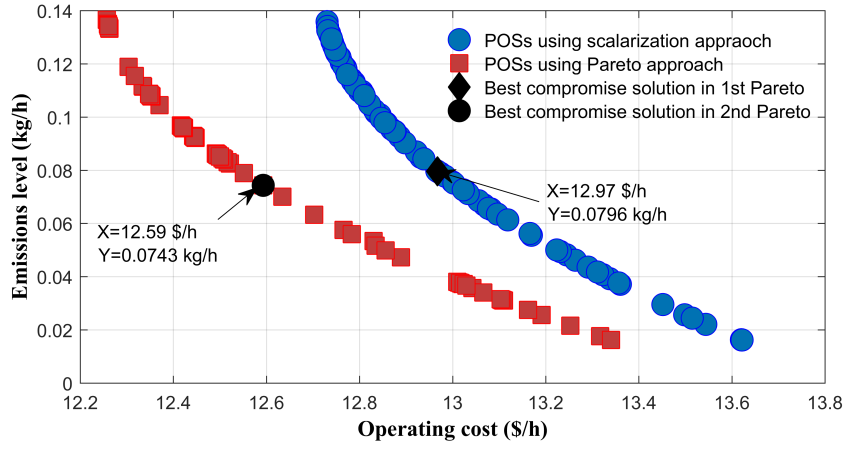

Fig. 7 Obtained POSs using both approaches considering the operating cost and emissions level as objective functions

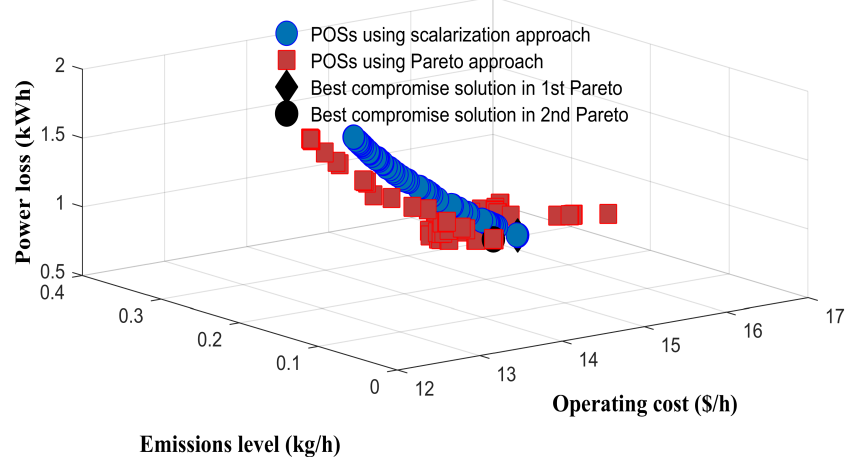

Fig. 8 Obtained POSs using both approaches considering simultaneously the three objective functions

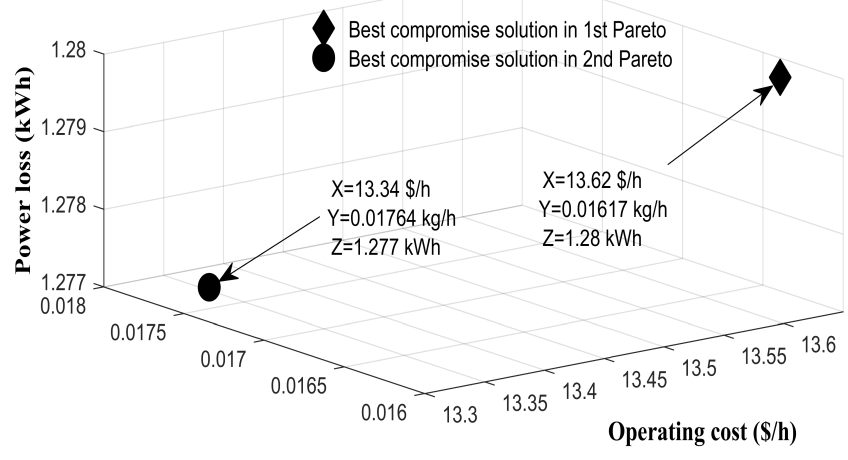

Emissions level $(\mathrm{kg} / \mathrm{h})$

Fig. 9 Obtained best compromise solution using both approaches considering simultaneously the three objective functions

\subsection{Daily Simulation of the MG Operation under Grid Connected Mode}

The MG power system under study, is equipped with RESs in the form of solar PV, BSS, and WT unit with the aim to achieve less dependence on the power generated from the CESs and a cost saving.

For this case study, the demand is primarily supplied by both RESs and the BSS during discharging cycles. Fig. 10 illustrates the daily produced power by both PV and WT unit, the optimal charging/discharging power of BSS based on a fuzzy logic control (Lagouir, Badri and Sayouti. 2021), and the evolution of the battery SoC. Where the maximum output power values are 
considered as $40 \mathrm{~kW}$ for PV unit and $45 \mathrm{~kW}$ for WT power source. The energy capacity of the BSS is set to $144 \mathrm{kWh}$, with a maximum charging, discharging power of $-20 \mathrm{~kW}, 20 \mathrm{~kW}$, respectively. While its SoC is bounded between $20 \%$ and $80 \%$, respectively.

As shown in Fig. 10, the initial capacity of the battery is $72 \mathrm{kWh}$ and during the daily MG operation the battery SoC is maintained at optimal levels, avoiding full charges-discharges cycles. In the figure, a positive value indicates that the battery generates power during discharging cycles, while a negative value means that the battery stores the excess of power for future use.

Moreover, it can be observed that, if the available power from both RESs and BSS during discharging cycles is not enough the match the load demand. The developed EMS incorporates the three dispatchable sources in the energy management, while starting the transaction with the main grid through exchanging power. The optimal generation of the installed CESs and the imported power from the main grid for daily MG operation are shown in Fig. 11. It is clear that in order to achieve, a reasonable compromise between the contradictory objective functions. The remaining load, which is defined as the difference between the actual load and the power output of both PV and WT modules including the generated power from the BSS during discharging cycles, is mainly supplied by the FC unit and MT unit. The DE, as the most expensive unit, was dispatched for a limited period of time and with less power generation, only when the remaining load becomes higher, or in case when the transaction with the main grid is inappropriate to get a better compromise between the considered objective functions. The proposed scenario proves the reliability and the efficiency of the developed EMS, since the supply of load is made without interruption, and without load shedding as shown in Fig. 12.

It is worth mentioning that the previously described figures are plotted using the Pareto method to handle the MOOD during $24 \mathrm{~h}$ operation of the DC microgrid system. Additionally, the considered daily load profile is assumed to be purely resistive, with a daily total energy demand of $11.1101 \mathrm{MWh}$ and a peak load of $204.7 \mathrm{~kW}$.

To further examine the performance of the proposed two methodologies for handling the MOOD problem. The results obtained using the Pareto method were compared with those provided using scalarization technique. Table 3 summarizes the obtained results using both approaches for a daily MG operation. The obtained simulation results have shown that the Pareto approach provides a considerable decrease in the daily operating cost by $28.96 \$$ day, a slight decrease in the daily power loss of converters from $419.79 \mathrm{kWh}$ to $419.29 \mathrm{kWh}$, while the daily pollutant gas emission was increased from $11.54 \mathrm{~kg} /$ day to $12.21 \mathrm{~kg} /$ day. This small increase is totally tolerable. The following formula is used to calculate the total daily treatment cost which is defined as the multiplication of the externality cost by its associated deviation in the daily emission level:

$C_{\text {treatment }}=\sum_{i=1}^{k} \chi_{k} \times\left(E m_{k, \text { Pareto }}-E m_{k, \text { Scalarization }}\right)$
Where

- $C_{\text {treatment }}$ is the total treatment cost of the pollutants related to the deviation in daily emissions level using both methods, and

- $\quad E m_{k, \text { Pareto }}, E m_{k, \text { Scalarization }}$ denote the daily emission level of emission type $k$ obtained using Pareto method and scalarization method, respectively.

The total daily treatment cost obtained using the data provided in Table 3 is $C_{\text {treatment }}=5.55 \$$ /day. Subtracting this value from the variance in the daily operating cost obtained using Pareto and Scalarization methods, a daily cost saving of $23.41 \$ /$ day is yielded. Therefore, the considerable reduction in the daily operating cost obtained using the Pareto method allows to compensate the slight increment in the daily emission level as well as a considerable cost saving.

By comparing Fig. 13 (a) and (b), it can be seen that the contribution rate of the main grid was increased from $8.43 \%$ to $8.70 \%$ when the Pareto technique is implemented to solve the MOOD problem. This increase could be explained by the fact that the Pareto method encourages importing power from the main grid as an appropriate alternative. This means more dependence on the power generated from the main grid. Which explains the slight rise in the daily pollutant emission level, due to the highest value of emission coefficients of the main grid used in this research work.

In summary, the Pareto method is most effective and outperforms the scalarization technique in terms of providing better quality solutions, easy to implement, handles the objective functions simultaneously and independently. Furthermore, it requires less computational time to solve the MOOD problem in MG. Since the total execution time using the Pareto technique for $24 \mathrm{~h}$ MG's operation is approximately $2015.59 \mathrm{~s}$ with an average computational time of $21 \mathrm{~s}$ for each time interval $\Delta \mathrm{T}$, using a personal computer with the following specifications: Processor speed of $2.20 \mathrm{GHz}$ and a memory RAM of $4 \mathrm{~GB}$.

Those are satisfactory reasons of choosing the Pareto approach based MOMVO as an optimization algorithm to handle the MOOD problem.

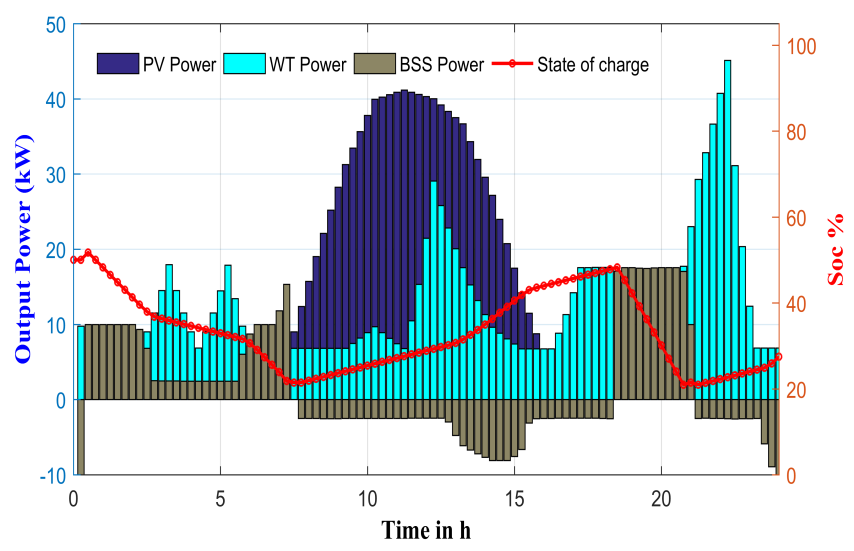

Fig. 10 Output power of RESs and the optimal charging/discharging cycles of BSS 
Citation: Lagouir, M., Badri, A., and Sayouti, Y. (2021), Solving Multi-Objective Energy Management of a DC Microgrid using Multi-Objective Multiverse Optimization. Int. Journal of Renewable Energy Development, 10(4), 911-922, doi: 10.14710/ijred.2021.38909 920 |

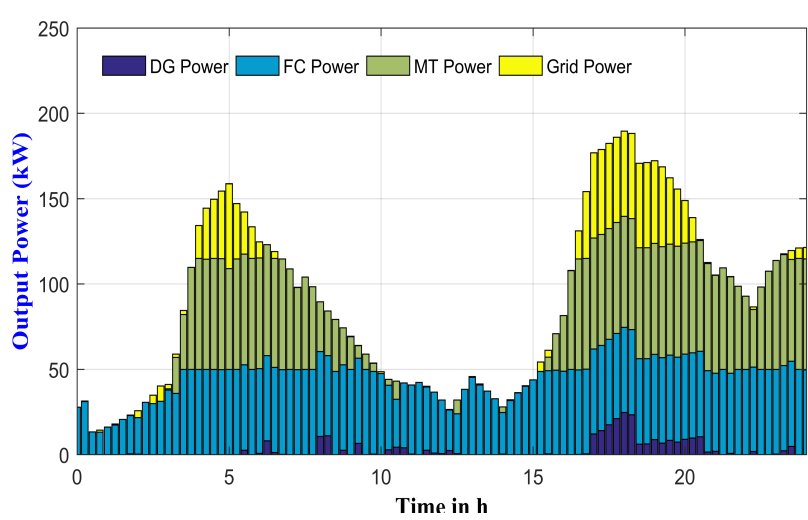

Fig. 11 Optimal power generation of CESs and the main grid

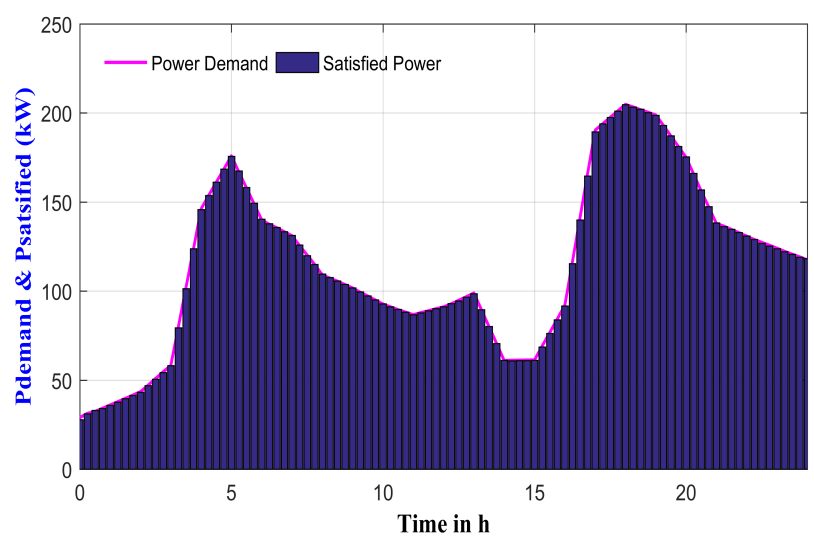

Fig. 12 Microgrid system power balance

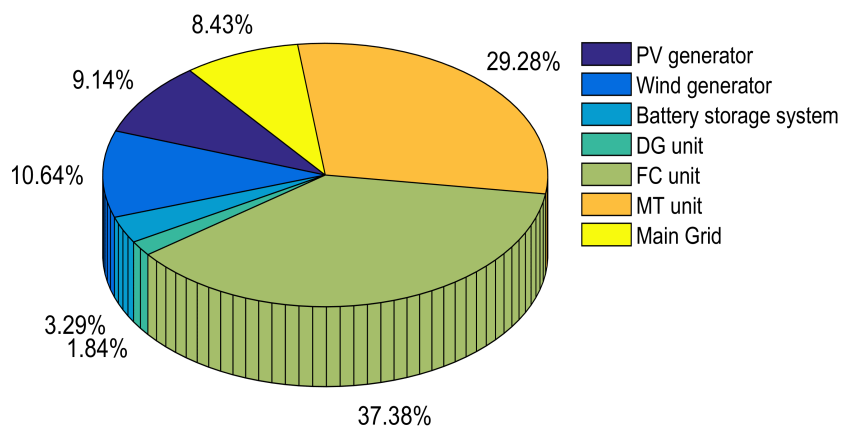

(a)

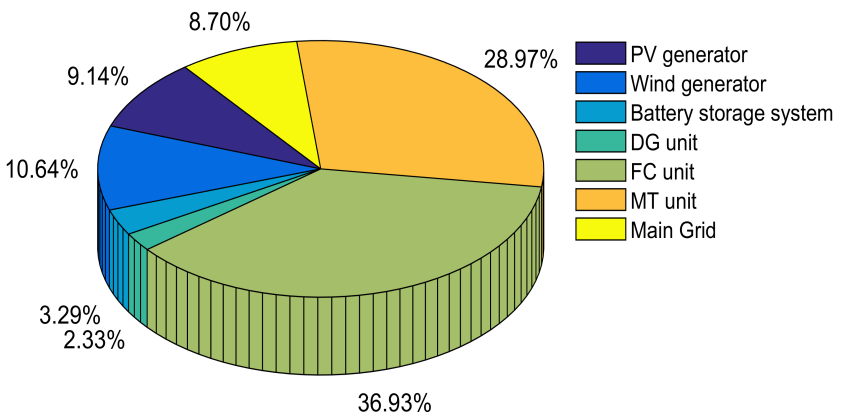

(b)

Fig. 13 Contribution of each generation source in power management using (a) scalarization approach, (b) Pareto approach
Table 3

Obtained simulation results using both approaches

\begin{tabular}{|c|c|c|}
\hline Output Variables & $\begin{array}{l}\text { Scalarization } \\
\text { approach }\end{array}$ & $\begin{array}{l}\text { Pareto } \\
\text { approach }\end{array}$ \\
\hline Daily Operating cost [\$/day] & 2826.0696 & 2797.1077 \\
\hline Daily Emissions level [kg/day] & 11.5432 & 12.2113 \\
\hline $\begin{array}{l}\text { Daily Power Loss of conversion } \\
\text { [kWh] }\end{array}$ & 419.7945 & 419.2941 \\
\hline $\begin{array}{l}\text { Daily Power Generated by } \\
\text { RESs [kWh] }\end{array}$ & 2240.3219 & 2240.3219 \\
\hline $\begin{array}{l}\text { Daily Power Generated by } \\
\text { CESs }[\mathrm{kWh}]\end{array}$ & 7755.0602 & 7724.6197 \\
\hline $\begin{array}{l}\text { Daily Power Generated by FC } \\
{[\mathrm{kWh}]}\end{array}$ & 4231.8701 & 4181.2486 \\
\hline $\begin{array}{l}\text { Daily Power Generated by MT } \\
\text { [kWh] }\end{array}$ & 3315.1929 & 3279.9245 \\
\hline $\begin{array}{l}\text { Daily Power Generated by DE } \\
\text { [kWh] }\end{array}$ & 254.1582 & 263.4466 \\
\hline $\begin{array}{l}\text { Daily Imported Power from } \\
\text { main grid [kWh] }\end{array}$ & 954.4909 & 984.9274 \\
\hline $\begin{array}{l}\text { Daily Emission level of } \mathrm{NO}_{\mathrm{x}} \\
\text { [kg/day] }\end{array}$ & 4.3048 & 4.8942 \\
\hline $\begin{array}{l}\text { Daily Emission level of } \mathrm{SO}_{2} \\
\text { [kg/day] }\end{array}$ & 1.7858 & 1.8518 \\
\hline $\begin{array}{l}\text { Daily Emission level of } \mathrm{CO}_{2} \\
\text { [kg/day] }\end{array}$ & 5.4525 & 5.4654 \\
\hline Computational time $[\mathrm{s}]$ & 2956.6186 & 2015.5863 \\
\hline
\end{tabular}

4.3. Analysis of the Impact of the Exchanged Power Range with the Main Grid on the Formulated Optimization Dispatch Problem

In Fig. 14 and Fig. 15, respectively, the impact of changing the range of the exchanged power with the main grid on the formulated optimization dispatch problem was analyzed. The results show that the adjustment of the maximum power exchanged with the main grid will affect the considered objective functions. From the simulation results, it is clearly seen that in order to ensure a better compromise between the contradictory objective functions. The transaction with the main grid is taken as the third best alternative to be used.

By comparing, the results curve of Fig. 14 and Fig. 15 , respectively. They show that extending the range of the transaction with the main grid is most beneficial. It provides a considerable reduction in the daily operating cost and the pollutant emission level of the MG system by almost $15.55 \$ /$ day and $1.88 \mathrm{~kg} /$ day, respectively. Whereas, extending the range of the exchanged power with the main grid may result in higher power loss of the converters from $413.48 \mathrm{kWh}$ to $424.82 \mathrm{kWh}$, when the generated power is increased from $40 \mathrm{~kW}$ to $120 \mathrm{~kW}$. This is mainly due to the high power loss coefficient of the main grid converter.

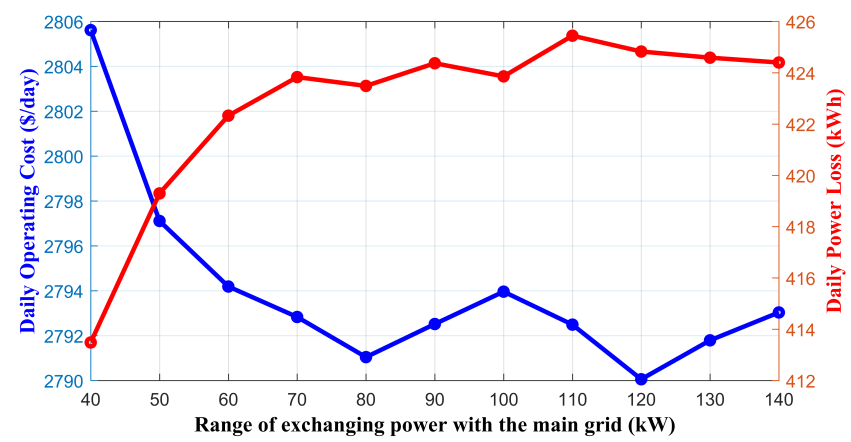

Fig. 14 Impact of range of exchanging power with the main grid on the daily operating cost and power loss of converters 


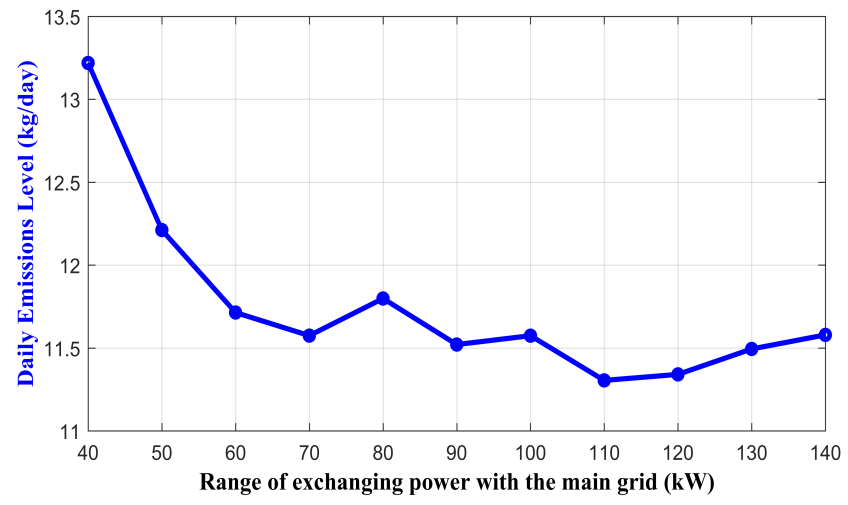

Fig. 15 Impact of range of exchanging power with the main grid on the daily emissions level

Expanding the range of the transaction with the main grid to $120 \mathrm{~kW}$, will totally favor the supply from the main grid, instead of the power generated from the DE. Therefore, in addition to the generation of both RESs and the BSS during discharging cycles. The remaining load will be mainly supplied by the $\mathrm{FC}$ and MT unites. While encouraging the import of power from the external grid instead of using the DE.

\section{Conclusion}

This paper deals with the optimization dispatch problem in MG power system, and proposes two approaches to solve the MOOD issue. The problem was formulated as minimizing the operating cost, pollutant emission level of $\left(\mathrm{NO}_{\mathrm{x}}, \mathrm{SO}_{2}\right.$ and $\left.\mathrm{CO}_{2}\right)$ and the power loss of conversion devices.

The scalarization and Pareto techniques are both adopted to obtain Pareto optimal solutions. In addition, a fuzzy logic theory is employed to find the best compromise solution. Both methods are evaluated in terms of responding to the system load and technical constraints, effectiveness and accuracy to provide better distribution of solutions and better quality results in less computational time. The simulation results demonstrate the reliability of the proposed Pareto method in dealing with the MOOD problem in MG system, having achieved a considerable reduction in the operating cost by almost $28.96 \$$ day, a small decreased in the power loss of converters by almost $0.5 \mathrm{kWh}$ per day. Whilst a slight rise may be observed in the value of the daily pollutant emission level from 11.54 $\mathrm{kg} /$ day to $12.21 \mathrm{~kg} /$ day, which can be totally compensated due to the considerable decrease in the daily operating cost achieved using the Pareto method.

Furthermore, the impact of the range of exchanging power with the main grid were analyzed. The obtained simulation results show, that expanding the range of the exchanged power, will guarantee a cost saving of 15.55 $\$$ /day and a considerable decrease in daily MG's pollutant emission level by almost $1.88 \mathrm{~kg} /$ day. Whereas the daily power loss of converters will become higher, with an increase of $11.34 \mathrm{kWh}$, when expanding the range of the transaction with the main grid from $40 \mathrm{~kW}$ to $120 \mathrm{~kW}$.

Through the numerous advantages that the evolutionary multi-objective algorithms present to approximate the Pareto set and to handle the non-convex multi-objective optimization problem. The future work involves the implementation of various evolutionary multi-objective optimization for handling the MOOD problem in $\mathrm{MG}$ and compare their performance, while taking into account challenging constraints such as valvepoint effects, prohibited operating zone and ramp rate limits. Besides solving the MOOD, the unit commitment which is the process of deciding when and which generating units to start-up and shutdown is another issue that should be addressed in upcoming studies.

\section{References}

Abdullah, M. N., Bakar, A. H. A., Rahim, N. A. and Mokhlis, H. (2015). Modified Particle Swarm Optimization for EconomicEmission Load Dispatch of Power System Operation, Turkish Journal of Electrical Engineering \& Computer Sciences, 23(Sup.1), 2304-2318; doi: 10.3906/elk-1307-204

Aghajani, G. and Ghadimi, N. (2018). Multi-Objective Energy Management in a Micro-grid, Energy Reports, 4, 218-225; doi: 10.1016/j.egyr.2017.10.002

Alazemi, F. Z. and Hatata, A. Y. (2019). Ant Lion Optimizer for Optimum Economic Dispatch Considering Demand Response as a Visual Power Plant, Electric Power Components and Systems, 47(6-7), 629-643; doi: 10.1080/15325008.2019.1602799

Aluisio, B., Dicorato, M., Forte, G. and Trovato, M. (2017). An Optimization Procedure for Microgrid Day-ahead Operation in the Presence of CHP Facilities, Sustainable Energy, Grids and Networks, 11,34-45; doi: 10.1016/j.segan.2017.07.003

Alvarado-Barrios, L., Rodríguez del Nozal, A., Tapia, A., Martínez-Ramos, J. L. and Reina, D. G. (2019). An Evolutionary Computational Approach for the Problem of Unit Commitment and Economic Dispatch in Microgrids under Several Operation Modes, Energies, 12(11), 2143; doi: 10.3390/en12112143

Augusto, O. B., Bennis, F. and Caro, S. (2012). A new method for decision making in multi-objective optimization problems, Pesquisa Operacional, 32(2), 331-369; doi: 10.1590/S0101$\underline{74382012005000014}$

Cheng, J., Dongliang, D., Cheng, X., Yang, L. and Cui, S. (2020). Probabilistic Microgrid Energy Management with Interval Predictions, Energies, 13(12), 3116; doi: 10.3390/en13123116

Contreras, S. F., Cortes, C. A. and Myrzik, J. M. A. (2019). Optimal Microgrid Planning for Enhancing Ancillary Service Provision, Journal of Modern Power Systems and Clean Energy, 7(4), 862-875; doi: 10.1007/s40565-019-0528-3

Dey, A. and Choudhury, A. B. (2017). A comparative study between scalarization approach and Pareto approach for multi-objective optimization problem using Genetic Algorithm (MOGA) formulated based on superconducting fault current limiter, in 1st IEEE International Conference on Power Electronics, Intelligent Control and Energy Systems, ICPEICES 2016. Institute of Electrical and Electronics Engineers Inc. doi: 10.1109/ICPEICES.2016.7853238

Dey, B., Shivam, K. and Bhattacharyya, B. (2019). Energy management of various microgrid test systems using swarm evolutionary algorithms, in Distributed Energy Resources in Microgrids: Integration, Challenges and Optimization. Elsevier, 323-341; doi: 10.1016/B978-0-12-817774-7.00012-0

Fathy, A. and Rezk, H. (2018). Multi-verse optimizer for identifying the optimal parameters of PEMFC model, Energy, 143, 634-644; doi: 10.1016/j.energy.2017.11.014

Feng, J., Zhang, J., Wang, C., Jiang, R. and Xu, M. (2020). MultiObjective Economic Scheduling of a Shipboard Microgrid Based on Self-Adaptive Collective Intelligence DE Algorithm, IEEE Access, 8, 73204-73219; doi: 10.1109/ACCESS.2020.2988530

Ghiasi, M., Niknam, T., Dehghani, M., Siano, P., Alhelou, H. H. and Al-Hinai, A. (2021). Optimal Multi-Operation Energy 
Management in Smart Microgrids in the Presence of RESs Based on Multi-Objective Improved DE Algorithm: CostEmission Based Optimization, Applied Sciences, 11(8), 3661; doi: 10.3390/app11083661

Gunantara, N. (2018). A review of multi-objective optimization: Methods and its applications, Cogent Engineering., 5(1), 1-16; doi: 10.1080/23311916.2018.1502242

Haseeb, M., Kazmi, S. A. A., Malik, M. M., Ali, S., Bukhari, S. B. A. and Shin, D. R. (2020). Multi Objective Based Framework for Energy Management of Smart Micro-Grid, IEEE Access, 8, 220302-220319; doi: 10.1109/ACCESS.2020.3041473

Hatata, A. Y. and Hafez, A. A. (2019). Ant Lion Optimizer Versus Particle Swarm and Artificial Immune System for Economical and Eco-Friendly Power System Operation, International Transactions on Electrical Energy Systems, 29(4); doi: 10.1002/etep.2803

Hou, H., Xue, M., Xu, Y., Xiao, Z., Deng, X., Xu, T., Liu, P. and Cui, R. (2020). Multi-Objective Economic Dispatch of a Microgrid Considering Electric Vehicle and Transferable Load, Applied Energy, 262, 114489; doi: 10.1016/j.apenergy.2020.114489

Kamboj, V. K., Bhadoria, A. and Bath, S. K. (2017). Solution of Non-Convex Economic Load Dispatch Problem for SmallScale Power Systems Using Ant Lion optimizer, Neural Computing and Applications, 28, 2181-2192; doi: 10.1007/s00521-015-2148-9

Lagouir, M., Badri, A. and Sayouti, Y. (2021). Multi-Objective Optimization Dispatch Based Energy Management of A Microgrid Running Under Grid Connected and Standalone Operation Mode, International Journal of Renewable Energy Development, $\quad 10(2), \quad 333-343 ; \quad$ doi: 10.14710/IJRED.2021.34656

Liu, H., Ji, Y., Zhuang, H. and Wu, H. (2015). Multi-Objective Dynamic Economic Dispatch of Microgrid Systems Including Vehicle-to-Grid, Energies, 8(5), 4476-4495; 10.3390/en8054476

Lokeshgupta, B. and Sivasubramani, S. (2018). Multi-objective dynamic economic and emission dispatch with demand side management, International Journal of Electrical Power and Energy Systems, 97, 334-343; doi: 10.1016/j.ijepes.2017.11.020

Mirjalili, S., Jangir, P., Mirjalili, S. Z., Saremi, S. and Trivedi, I. N. (2017). Optimization of problems with multiple objectives using the multi-verse optimization algorithm, KnowledgeBased Systems, 134, 50-71; doi: 10.1016/j.knosys.2017.07.018

Mirjalili, S., Mirjalili, S. M. and Hatamlou, A. (2016). Multi-Verse Optimizer: a nature-inspired algorithm for global optimization, Neural Computing and Applications, 27(2), 495-513; doi: 10.1007/s00521-015-1870-7

Mohamed, F. A. and Koivo, H. N. (2012). Online Management Genetic Algorithms of Microgrid for Residential Application, Energy Conversion and Management, 64, 562-568; doi: 10.1016/j.enconman.2012.06.010

Mondal, S., Bhattacharya, A. and nee Dey, S. H. (2013). MultiObjective Economic Emission Load Dispatch Solution Using gravitational Search algorithm and considering wind Power Penetration, International Journal of Electrical Power \& Energy Systems, 44(1), 282-292; doi: 10.1016/j.ijepes.2012.06.049

Moradi, H., Esfahanian, M., Abtahi, A. and Zilouchian, A. (2018). Optimization and Energy Management of a Standalone Hybrid Microgrid in the Presence of Battery Storage System, Energy, 147, 226-238; doi: 10.1016/j.energy.2018.01.016

Murty, V. V. S. N. and Kumar, A. (2020). Multi-Objective Energy Management in Microgrids with Hybrid Energy Sources and
Battery Energy Storage Systems, Protection and Control of Modern Power Systems, 5(2); doi: 10.1186/s41601-019-0147-z Nemati, M., Braun, M. and Tenbohlen, S. (2018). Optimization of Unit Commitment and Economic Dispatch in Microgrids based on Genetic Algorithm and Mixed Integer Linear Programming, Applied Energy, 210, 944-963; doi: 10.1016/j.apenergy.2017.07.007

Rodríguez del Nozal, A., Tapia, A., Alvarado-Barrios, L. and Reina, D. G. (2020). Application of genetic algorithms for unit commitment and economic dispatch problems in microgrids, in Studies in Computational Intelligence. Springer, 139-167; doi: 10.1007/978-3-030-33820-6 6

Stafford, R. (2021). Random Vectors with Fixed Sum, MATLAB Central File Exchange. Available at: https://www.mathworks.com/matlabcentral/fileexchange/970 0-random-vectors-with-fixed-sum (Accessed: 7 July 2021)

Sundaram, A. (2020). Multiobjective multi-verse optimization algorithm to solve combined economic, heat and power emission dispatch problems, Applied Soft Computing Journal, 91, 106195; doi: 10.1016/j.asoc.2020.106195

Taha, M. S., Abdeltawab, H. H. and Mohamed, Y. A. I. (2018). An Online Energy Management System for a Grid-Connected Hybrid Energy Source, IEEE Journal of Emerging and Selected Topics in Power Electronics, 6(4), 2015-2030; doi: 10.1109/JESTPE.2018.2828803

Van, T. P., Snasel, V. and Nguyen, T. T. (2020). Antlion Optimization Algorithm for Optimal Non-Smooth Economic Load Dispatch, International Journal of Electrical and Computer Engineering (IJECE), 10(2), 1187-1199; doi: 10.11591/ijece.v10i2.pp1187-1199

Wang, B., Sechilariu, M. and Locment, F. (2012). Intelligent DC microgrid with smart grid communications: Control strategy consideration and design, IEEE Transactions on Smart Grid, 3(4), 2148-2156; doi: 10.1109/TSG.2012.2217764

Wang, T., He, X. and Deng, T. (2019). Neural Networks for Power Management Optimal Strategy in Hybrid Microgrid, Neural Computing and Applications, 31(7), 2635-2647; doi: 10.1007/s00521-017-3219-x

Wang, Z., Zhu, Q., Huang, M. and Yang, B. (2017). Optimization of Economic/Environmental Operation Management for Microgrids by Using Hybrid Fireworks Algorithm, International Transactions on Electrical Energy Systems, 27(12); doi: 10.1002/etep.2429

Wu, H., Liu, X. and Ding, M. (2014). Dynamic Economic Dispatch of a Microgrid: Mathematical Models and Solution Algorithm, International Journal of Electrical Power \& Energy Systems, 63, 336-346; doi: 10.1016/j.ijepes.2014.06.002

Wu, X., Cao, W., Wang, D. and Ding, M. (2019). A Multi-Objective Optimization Dispatch Method for Microgrid Energy Management Considering the Power Loss of Converters, Energies, 12(11), 2160; doi: 10.3390/en12112160

Yuan, X., Zhang, B., Wang, P., Liang, J., Yuan, Y., Huang, Y. and Lei, X. (2017). Multi-Objective Optimal Power Flow based on Improved Strength Pareto Evolutionary Algorithm, Energy, 122, 70-82; doi: 10.1016/j.energy.2017.01.071

Zhang, Q., Ding, J., Shen, W., Ma, J. and Li, G. (2020). Multiobjective Particle Swarm Optimization for Microgrids Pareto Optimization Dispatch, Mathematical Problems in Engineering, 2020; doi: 10.1155/2020/5695917

Zhang, Y., Gong, D. W. and Ding, Z. (2012). A bare-bones multiobjective particle swarm optimization algorithm for environmental/economic dispatch, Information Sciences, 192, 213-227; doi: 10.1016/j.ins.2011.06.004 